\title{
Narraciones políticas y procesos de enmarcamiento del discurso de las asociaciones del Foro para la Integración Social de los Inmigrantes de España
}

\section{Rosa Maria Verdugo Matés}

Universidade de Santiago de Compostela. Departamento de Economía Aplicada

Avenida do Burgo das Naçons, s/n. 15782 Santiago de Compostela earosi@usc.es

\section{Águeda Gómez Suárez}

Universidade de Vigo

Departamento de Socioloxía, Ciencias Políticas, Administración e Filosofía

Campus Universitario As Lagoas-Avd. Castelao, s/n. 32004 Ourense

agueda@uvigo.es

\section{Resumen}

En este artículo, se realiza un pormenorizado análisis en torno a los mensajes políticos construidos por las asociaciones de inmigrantes que forman parte del Foro para la Integración Social de los Inmigrantes de España. Para ello, se ha optado por el uso del marco teórico del «análisis de marcos» (McAdams, McCarthy y Zald, 1999; Snow, Benford y Hunt, 1993), categoría analítica proveniente del «interaccionismo simbólico» de Goffman (1974), y que se considera como un elemento central en la formación de la identidad de los actores sociales y en su «actuación social», así como en la definición de problemáticas, causas y soluciones de sus reivindicaciones. Secundariamente, se esbozan las resonancias de sus propuestas y de sus programas políticos y sociales en diferentes "audiencias», con el objetivo de evaluar el impacto político de sus discursos.

Palabras clave: procesos de enmarcamiento, narraciones políticas, movimiento asociativo inmigrante, Foro para la Integración Social de los Inmigrantes, España.

Abstract. Political narrations and frame processes concerning the speech of the associations involved in the Forum for the Social Integration of Spain Inmigrants

This article carries out a detailed analysis of the political messages constructed by the immigrants associations which are part of the Forum for the Social Integration of the Spain Immigrants. The author has opted to make use of the «frame analysis» theoretical mark (McAdams, McCarthy and Zald, 1999; Snow, Benford and Hunt, 1993), analytic category coming from the «symbolic interactionism» of Goffman (1974), considered as a central element in the identity formation of the social actors and in their "social performance», as well as in the definition of problematic, causes and solutions of their demands. Secondarily, the author addresses the resonance of their proposals and their political and social programs in different «audiences» in order to evaluate the political impact of their speeches.

Key words: immigration, social politics, asociacionism, frame analysis, political speeches. 


\section{Sumari}

\section{Introducción}

2. Marco teórico y metodología: el «análisis de marcos»

3. Foro para la Integración Social de los Inmigrantes

4. Procesos de construcción de los marcos de interpretación
5. Relación entre los marcos y las situaciones analizadas

6. Impacto en las audiencias y resonancia de los discursos

7. Conclusiones

Bibliografía

\section{Introducción}

La inmigración no es un fenómeno reciente, pero en la última década se ha convertido en una cuestión relevante para la mayoría de los países desarrollados, de forma que se plantean una serie de interrogantes en torno a múltiples temas sobre recepción de los inmigrantes, multiculturalismo, derechos humanos, integración, políticas de ciudadanía, etc. Actualmente, existen múltiples trabajos que analizan las causas y los contextos en los que se producen las migraciones (Peces-Barba y otros, 1995; Pérez Luño, 1995), pero son menos numerosas las investigaciones que tratan las diferentes expresiones políticas en torno a los posicionamientos de los inmigrantes organizados relativamente a su situación en las sociedades de acogida.

Si se analiza el tratamiento del fenómeno migratorio en Europa, se observa que éste se caracteriza, al menos hoy en día, por el diseño de una estrategia más bien policial, con ausencia de una línea clara en materia de integración (Martínez de Pisón y Giró Miranda, 2003: 34). Y este esquema está también presente en España, donde el control de flujos se sistematiza a través de la política de cuotas (el denominado "contingente») que se basa en dos aspectos: el cuantitativo, que establece un número de trabajadores extranjeros dependiendo de la situación estatal del empleo español, y el cualitativo, que selecciona a determinados tipos de inmigrantes en función de las necesidades existentes. Por lo que se refiere a la política de integración, no existe un diseño claro, aunque se dice que el objetivo es acabar con la discriminación y el racismo.

El objetivo de este artículo es analizar una de las dimensiones menos estudiadas en torno a esta temática, aquélla referida al discurso de las asociaciones de inmigrantes que forman parte del Foro para la Integración Social de los inmigrantes de España, y de las consiguientes opciones ideológicas de las mismas. Hasta la actualidad, el estudio de las organizaciones sociales se ha caracterizado por la polarización de enfoques, derivado de las diferentes concepciones sobre las mismas (Cohen y Arato, 2000; McAdam, McCarthy y Zald, 1999; Tarrow, 1997). Cada vez se está generando un consenso metodológico y analítico sobre la necesidad de evaluar los procesos cognitivos de interpretación, atribución y construcción del discurso ideológico, a través de la matriz 
teórica del «análisis de marcos». Esta teoría pretende adentrarse en el mundo de las estructuras cognitivas, las ideas, los mitos, los sueños, la cultura, la memoria colectiva, etc. de los movimientos sociales, mediante el estudio de los procesos de construcción de su percepción de la realidad que ayudan, favorecen y promueven la acción colectiva. Los «marcos de interpretación» actúan como mediadores entre las «oportunidades» y la «movilización» a través de este proceso de construcción a escala mental (Show y otros, 1993).

El análisis de las narraciones escritas y orales de los líderes de las diferentes organizaciones de inmigrantes pertenecientes al Foro para la Integración Social de los Inmigrantes, órgano consultivo creado para la elaboración de la política de extranjería española, ha permitido obtener un repertorio sistematizado de las diferentes estructuras discursivas de estas asociaciones y ha facilitado la comprensión de sus argumentos legitimadores, la identificación de sus intereses y la definición de sus objetivos. Este estudio únicamente pretende aportar un enfoque sobre las estructuras cognitivas de las asociaciones de inmigrantes del mencionado foro. En próximas investigaciones, se intentará completar este análisis examinando los «recursos de movilización» y las "oportunidades políticas» de estas asociaciones de inmigrantes seleccionadas (McAdam, McCarthy y Zald, 1999).

\section{Marco teórico y metodología: el «análisis de marcos»}

Para iniciar este estudio en torno a los principales discursos de las organizaciones de inmigrantes del Foro para la Integración Social de los Inmigrantes, se ha optado por analizar sus mensajes desde la perspectiva metodológica que ofrecen los recientemente elaborados «marcos de interpretación» ${ }^{1}$.

Esta propuesta teórica proviene de la confluencia de teorías que se generaron con el fin de dar respuesta científica a la oleada de movimientos sociales novedosos que agitaron Europa y EEUU desde la década de 1960 y para los que las explicaciones tradicionales del marxismo y el funcionalismo no parecían satisfactorias. Es por ello por lo que, en la actualidad, existe un creciente acuerdo entre los diferentes analistas sobre la necesidad de integración teórica de, al menos, tres elementos: las oportunidades políticas, las estructuras de movilización y los procesos sociales de interpretación de la realidad y asignación de significado (McAdam y otros, 1999: 111), siendo ésta última la que vamos a analizar en este artículo. Estas teorías provienen fundamentalmente de la obra de dos autores trascendentales: el economista Mancur Olson, que, con su aplicación de la teoría de juegos al movimiento social, alumbró la «teoría de la elección racional», y Charles Tilly, un especialista en sociología histórica, que desarrolló la «teoría de la movilización de recursos» y de las «oportunidades políticas». Posteriormente, el análisis de la obra del sociólogo

1. Ver: McAdams, McCarthy y Zald (1999); Tarrow (1997); Snow, Benford y Hunt (1993), e Ibarra y Tejerina (1998). 
canadiense Irving Goffman aporta un nuevo enfoque, con el fin de completar las limitaciones teóricas de los planteamientos de Olson y Tilly. La principal obra de Goffman, "Análisis de marcos», es un ensayo sobre "la organización de la experiencia», donde se propone analizar el proceso mental de los individuos cuando reinterpretan la realidad de acuerdo con sus estructuras cognitivas, y a partir de lo cual se activa la movilización colectiva (Lorenzo Cardaso, 2001).

Este sistema teórico considera que las colectividades se organizan y tienden a definir estratégica y conscientemente una situación dada, a través de "procesos enmarcadores» que favorecen la interpretación de su realidad, con el fin de legitimarse a sí mismos y, en consecuencia, movilizar a los principales protagonistas para encabezar una acción colectiva que responda a sus intereses y objetivos más sustantivos.

De acuerdo con uno de los principales teóricos de esta corriente (Tarrow, 1997), el «análisis de marcos» es un sistema argumentativo que tiene la función de elaborar un diagnóstico para identificar los principales problemas y detectar sus causas, de forma que articula y moviliza de manera tendenciosa un despertar hacia la acción participativa en función de la gran capacidad de resonancia que ejercen sobre sus simpatizantes y agregados. Como ya se ha indicado anteriormente, esta categoría analítica, el frame, proviene del «interaccionismo simbólico» de Goffman (1974), que lo interpreta como un elemento central en la formación de la identidad y en la definición de sus adversarios. El «enmarque» es el resultado agregado de experiencia personal, memoria colectiva y prácticas objetivadas que habitualmente asociamos al concepto de "cultura». Las tradiciones, a menudo personificadas en prácticas rituales, pueden servir de soporte a la actividad del movimiento social como un recurso para la movilización.

Esta categoría analítica se entiende hoy como un elemento central en la formación de la identidad de los actores sociales y en su "actuación social» (performance). Esta forma de operar tiene como finalidad proyectar una imagen ante los demás que genere ciertas impresiones en el auditorio y, al mismo tiempo, definir problemáticas, causas y soluciones véase el gráfico 1.

Para Gamson (1990), hay tres variables que generan y determinan los «procesos de enmarcamiento" construidos por los propios movimientos sociales. En primer lugar, el elemento de «injusticia» que parte de una hot cognitions o "cuestión caliente», que provoca sentimientos de indignación. En segundo lugar, el elemento de la «eficacia» o la valoración de las probabilidades de éxito que el movimiento realiza sobre la consecución de sus objetivos. Por último, el elemento identitario del propio actor social que ayuda a diferenciar el «nosotros» del «ellos» (Snow, Benford y Hunt, 1993). Siguiendo a uno de los principales exponentes de esta teoría, se considera que las estructuras del marco tipo ideal están constituidas por las «dimensiones del enmarcamiento» de las áreas temáticas a las que se refiere y por las «estrategias de enmarcamiento» o técnicas utilizadas por los movimientos sociales para interpretar cada área temática (Gerhards, 1995), véase la tabla 1. 


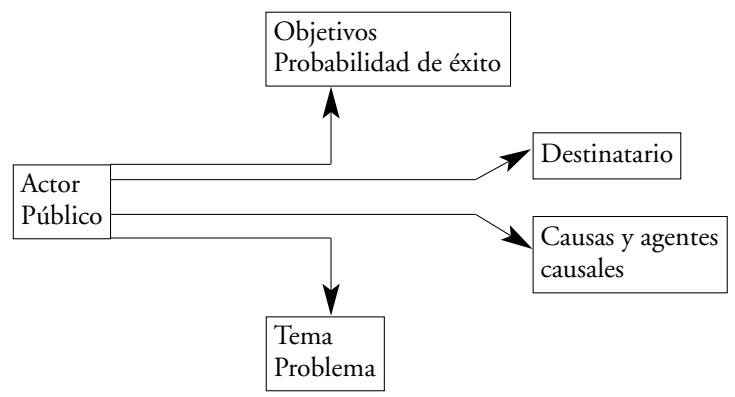

Gráfico 1. Esquema de un marco.

Fuente: elaboración propia, sobre la base del esquema de Gerhards, 1995: 228.

Tabla 1. Marco metodológico de análisis.

Dimensiones de enmarcamiento Estrategias de enmarcamiento

Indicar una cuestión del debate público (issue).

Definirla como un problema Asignarle un concepto o eslogan; hacerla social (problem).

empíricamente creíble mediante una referencia real. Concretar el problema refiriéndolo a la experiencia cotidiana; situarlo en un contexto o esquema más amplio; dramatizarlo.

Localizar las causas y los agentes causales del problema

(cause, causal agent).

Asignarles un concepto peyorativo; atribuirlas a actores colectivos externos; personalizar a los actores responsables; atribuirles intención e intereses particulares; moralizarlos.

Interpretar los objetivos (goal).

Encontrar un concepto eslogan; mostrar los beneficios de los afectados y medios para conseguirlo; esquematizar.

Interpretar las probabilidades de éxito Hacer referencias históricas de otros éxitos; de los esfuerzos (success). definir el número de posibles participantes.

Encontrar y caracterizar al destinatario Personalizar el destinatario, atribuirle de la protesta (addresses). intención; moralizarlo; considerarlo sospechoso de corrupción.

Justificarse como actores legítimos de la protesta (public actor).
Mostrar que representan intereses colectivos e individuales, autocaracterizarse con un valor social central; reclutar personas e instituciones dignas de confianza; dar credibilidad a sus temas e interpretaciones.

Fuente: elaboración propia, a partir de Gerhards, 1995, e Ibarra y Tejerina, 1998. 
La argumentación que a continuación se desarrolla intenta describir las dimensiones y estrategias centrales de «enmarcamiento» en el discurso ideológico de las organizaciones de inmigrantes, a partir del análisis de los documentos y de las declaraciones públicas de sus dirigentes. En concreto, para conocer el discurso de las asociaciones de inmigrantes del Foro, hemos analizado, por una parte, diversos documentos escritos elaborados por las asociaciones del Foro para difundir sus objetivos y, por otra, la información contenida en sus páginas web. En concreto, analizamos las actividades realizadas (formativas, lúdicas, de asesoría y apoyo, informativas, entre otras), los servicios ofertados (de tipo jurídico, lingüístico, etc.) y el ideario político-ideológico (declaraciones, manifiestos, programas, proclamas, etc.). Además, y para completar información que no se hacía explicita en estos documentos, hemos realizado entrevistas semiestructuradas a los representantes de estas asociaciones. Todo ello nos ha permitido conocer los procesos sociales de interpretación de la realidad y asignación de significado de las asociaciones del Foro para la Integración Social de los Inmigrantes.

En este artículo, hemos seguido el esquema propuesto por el «análisis de marcos», es decir, hemos seleccionado fragmentos textuales donde las organizaciones se autodefinen, presentan sus objetivos, explican su focalización temática prioritaria, exponen sus problemáticas, indican las causas y los agentes causales de las mismas y aportan las posibles soluciones. La principal limitación de esta selección es que se ha incidido en el análisis de aquellos aspectos más politizados y dramatizados (hot cognitions) (Gerhards, 1995) y se han marginado aquéllos otros referidos a cuestiones más descriptivas. En cualquier caso, esta forma de operar responde a los objetivos de nuestra investigación, a saber, analizar los principales discursos de las asociaciones de inmigrantes del Foro.

\section{Foro para la Integración Social de los Inmigrantes}

Hoy en día, la legislación española en materia de extranjeros, al igual que la del resto de países de la Unión Europea, diferencia entre los inmigrantes comunitarios y los extracomunitarios, de forma que los primeros se regulan por el Régimen Comunitario y los segundos por el Régimen General. En el último lustro, cambió significativamente la legislación que rige para los extranjeros extracomunitarios que residen en España ${ }^{2}$. Los cambios introducidos responden a la necesidad de homogeneizar dentro de la Europa comunitaria la figura del extranjero. Efectivamente, para conseguir un verdadero mercado interior comunitario, había que suprimir las fronteras interiores y, en consecuencia, igualar

2. Así, la Ley Orgánica 4/2000, de 11 de enero, sobre derechos y libertades de los extranjeros en España y su integración social, substituyó a la Ley Orgánica 7/1985, de 1 de julio. Y con menos de un año de vigencia, la Ley Orgánica 4/2000 va a ser reformada a través de la Ley Orgánica 8/2000, de 22 de diciembre. Finalmente, se aprueba la Ley Orgánica 14/2003, de 20 de noviembre. 
los requisitos de entrada y permanencia para los inmigrantes extracomunitarios ${ }^{3}$ (La Calle Marcos, 2002).

Las reformas de la ley de extranjería aprobadas en España, lejos de equiparar los derechos y las libertades de los extranjeros con los derechos y las libertades de los españoles, fijan una diferenciación entre ciudadanía y nacionalidad. Se trata de una exclusión institucional, y se mantiene que la exclusión no existe, porque, por definición, los extranjeros, simplemente, no entran en el reparto (Solanes, 2000). Entre los pocos aspectos positivos de estas reformas, podemos destacar que, a partir de la Ley Orgánica 4/2000, se establece un título dedicado a la coordinación de los poderes públicos en temas de inmigración. Se trata del título IV, formado por los artículos $60^{4}, 61^{5}, 62^{6}$ y 63 . A través del artículo 63, Foro para la Integración Social de los Inmigrantes, se institucionaliza la participación de las asociaciones de inmigrantes en la elaboración de la política inmigratoria. El Foro está constituido, de forma tripartita y equilibrada, por representantes de las administraciones públicas, por asociaciones de inmigrantes y por organizaciones sociales de apoyo, como, por ejemplo, los sindicatos de trabajadores y organizaciones empresariales que tengan interés en el ámbito inmigratorio ${ }^{7}$. Se trata de un órgano consultivo que tiene como finalidad promover la participación y la integración social de los inmigrantes en la sociedad española.

El Foro para la Integración Social de los Inmigrantes es un órgano colegiado adscrito al Ministerio del Interior a través de la Delegación del Gobierno

3. En este sentido, en el año 1986, el Acta Única Europea institucionaliza la Cooperación Política Europea y, en el año 1990, se firma el Convenio de Schengen, que implica una paulatina supresión del control de las fronteras intracomunitarias y el reforzamiento de las extracomunitarias. Posteriormente, el Tratado de Maastricht (1992) incluye el denominado «tercer pilar», donde se tratan, entre otros, los temas de inmigración y de asilo. Y a través del Tratado de Amsterdam (1997) la Unión Europea se compromete a establecer progresivamente un espacio de libertad, de seguridad y de justicia común, de forma que todo lo referido a libre circulación de las personas, control de las fronteras exteriores, asilo, inmigración y cooperación judicial en materia civil pasa a formar parte del tercer pilar en un proceso gradual de varios años. En definitiva, la década de 1990 fue decisiva para el impulso de la política migratoria comunitaria: se asume la necesidad de abordar conjuntamente los temas de inmigración, se acuerda impermeabilizar las fronteras exteriores y se elaboran los primeros textos comunes para enfrentarse a la apertura de las fronteras interiores.

4. Artículo 60: Coordinación de los órganos de la Administración del Estado.

5. Artículo 61: El Consejo Superior de Política de Inmigración.

6. Artículo 62: Apoyo al movimiento asociativo de los inmigrantes.

7. En concreto, forman parte del Foro el presidente (nombrado por el Ministerio de Trabajo y Asuntos Sociales), dos vicepresidentes (uno elegido por los vocales de las asociaciones y organizaciones no gubernamentales y otro titular de la Secretaría General de Asuntos Sociales) y 31 vocales. Dentro de los vocales, 11 están en representación de las administraciones públicas y 20 son designados por el ministro de Trabajo y Asuntos Sociales de la siguiente forma: 8 en representación de las asociaciones de inmigrantes y refugiados, 9 en representación de las organizaciones no gubernamentales relacionadas con los inmigrantes y refugiados, 2 en representación de las organizaciones sindicales más significativas de España y 1 en representación de las organizaciones empresariales más representativas. 
para la extranjería y la inmigración. Anualmente, se seleccionan las asociaciones de inmigrantes que forman parte del Foro. Las asociaciones seleccionadas son aquéllas que tienen un mayor número de afiliados y que, en principio, son las que tienen un mayor peso dentro del movimiento asociativo inmigrante. Además, también se tiene en cuenta en la selección el peso de las diferentes nacionalidades de los extranjeros que residen en España, de forma que la composición del Foro respete esa ponderación. Actualmente, las asociaciones de inmigrantes que forman parte del Foro para la Integración Social de los Inmigrantes son:

ASCIB (Asociación Sociocultural Ibn Batuta).

- ATIME (Asociación de Trabajadores Inmigrantes Marroquíes).

- AICODE (Asociación Iberoamericana para la Cooperación, el Desarrollo y los Derechos Humanos).

- VOMADE (Voluntariado de Madres Dominicanas).

- Ari Perú.

- ACHE (Asociación de Chinos en España).

- AESCO (América-España, Solidaridad y Cooperación).

- ACULCO (Asociación Cultural por Colombia e Iberoamérica).

Antes de continuar, debemos indicar que existen otras asociaciones de inmigrantes en España. Sin embargo, el objetivo de este artículo es analizar el impacto de los discursos del asociativismo inmigrante español sobre el colectivo de extranjeros en particular y sobre la sociedad española en general, y precisamente son las asociaciones del Foro para la Integración Social de los Inmigrantes las que tienen una mayor capacidad para hacer llegar sus discursos a estas audiencias.

Prácticamente, todas estas asociaciones del Foro nacen en la década de 1990, y su nacimiento está vinculado, sin ninguna duda, al proceso de consolidación de las comunidades de inmigrantes y a la maduración de la inmigración en España. Además, dos acontecimientos marcaron un punto de inflexión en la historia de estas organizaciones. Por una parte, los brotes racistas y xenófobos registrados en los últimos años en la sociedad española ${ }^{8}$ y, por otra parte, las mencionadas reformas de la Ley de extranjería. Como resultado, las asociaciones de inmigrantes intensifican su lucha contra el racismo y la xenofobia, al tiempo que reivindican mayores cuotas de derechos y libertades para los inmigrantes. Entre los objetivos comunes de las asociaciones que forman parte del Foro, podemos destacar los siguientes:

- Proporcionar asesoría jurídica al inmigrante, para facilitar la obtención de la documentación necesaria para conseguir los permisos de residencia y de trabajo.

8. Podemos afirmar que, en la última década, dos fueron los actos racistas que tuvieron mayor trascendencia en España. El primero, el asesinato de la dominicana Lucrecia Pérez, en el año 1992 y, el segundo, los lamentables enfrentamientos que tuvieron lugar entre autóctonos e inmigrantes en la localidad de El Ejido en el año 2000. 
- Defender los derechos de los trabajadores inmigrantes y facilitar su inserción laboral, a través de la prestación de servicios de información, orientación y asesoramiento.

- Promover la integración social y cultural de los inmigrantes desde una perspectiva intercultural, es decir, enseñando a los inmigrantes los valores culturales de su país de origen, pero también los valores culturales de la sociedad española?

Con la proclamación de estos objetivos, se evidencia que el asociativismo inmigrante se ha concienciado de la limitación de los derechos y las libertades de los extranjeros en España y de la necesidad de organizarse para conseguirlos. Los derechos de los trabajadores extranjeros ocupan un lugar central en las reivindicaciones de las asociaciones del Foro, pero éstos no son los únicos que se reivindican. De hecho, se habla de integración social y cultural del extranjero, es decir, se lucha para que el extranjero sea un ciudadano más y no únicamente "trabajador invitado».

Todas las asociaciones del Foro comenzaron su trabajo de forma individualizada, pero, a medida que se fueron consolidando, iniciaron relaciones entre ellas, sobre todo en el ámbito estatal, aunque en algún caso también en el europeo e internacional. De las ochos asociaciones consideradas, es ATIME la que tiene más conexiones, tanto con otras asociaciones de inmigrantes como con otro tipo de organizaciones. De hecho, ATIME participa de forma activa en varios foros europeos (Foro Europeo para la Inmigración y Coordinadora de Asociaciones Demócratas de Inmigrantes Marroquíes en Europa) y españoles (Red Española de Lucha contra la Pobreza y la Exclusión Social y Consejo Estatal de ONG de Acción Social). Otras tres asociaciones, AICODE, VOMADE y AESCO, mantienen importantes vínculos interasociativos. AICODE es miembro del Foro Regional para la Integración CAM (Comunidad de Madrid), del Grupo de Apoyo del Forum de Inmigrantes de la Unión Europea en España y de la Asamblea Permanente de la Sociedad Civil por la Paz en Colombia. VOMADE intenta intensificar lazos con todas las asociaciones de inmigrantes, pero también con diversas ONG, sindicatos y otros colectivos y grupos sociales. Estos lazos ultrapasan el ámbito local, llegando a establecerse algunos incluso en el ámbito internacional. AESCO forma parte de la Red Europea

9. Con relación a la integración cultural, podemos distinguir dos grupos de asociaciones, dependiendo de si sus asociados tienen o no el castellano como lengua materna. Así, para el primer grupo, la integración lingüística no es necesaria, quedando la mencionada integración restringida al resto de los aspectos culturales, mientras que el segundo grupo precisa de un mayor esfuerzo para alcanzar la pretendida integración cultural. De las ocho asociaciones del Foro, tres están en esta segunda situación (ASCIB, ATIME y ACHE). De hecho, según pudimos comprobar, en estas asociaciones se da bastante importancia al aprendizaje de la lengua española. A tal efecto, existen numerosos cursos de lengua castellana, pero también servicios de traducción e interpretación para ayudar a realizar las gestiones ante la Administración a aquellos asociados que aún no tienen suficientes conocimientos de castellano. 
contra el Racismo y es miembro del Foro Regional para la Integración CAM. En el resto de asociaciones, las relaciones internacionales son limitadas, aunque son frecuentes las establecidas en el ámbito español.

La consolidación de las relaciones nacionales e internacionales de las asociaciones del Foro se ha hecho más intensa en los últimos años. Estas relaciones evidencian la necesidad que tienen los inmigrantes de buscar apoyos en su lucha a favor de los derechos y las libertades de los extranjeros. Además, si los diferentes estados de la Europa comunitaria elaboran conjuntamente una política de inmigración, es lógico que, para lograr el éxito de sus reivindicaciones, las asociaciones de inmigrantes asentadas en el territorio de la Unión Europea elaboren sus alternativas a esta política de forma coordinada.

Otro aspecto destacable es que, en mayor o menor medida, existe una orientación del trabajo de estas asociaciones hacia el país de origen de los inmigrantes. Los casos más significativos son los de AICODE, VOMADE, AESCO y ATIME. De hecho, entre los retos de estas organizaciones se recoge de forma explícita la cooperación con el país de origen de los inmigrantes. Entre los objetivos de AICODE está el de promocionar, desarrollar y consolidar programas orientados a la divulgación y defensa de los principios de la cooperación al desarrollo con los países y pueblos de América Latina. Por su parte, VOMA$\mathrm{DE}$ incluye entre sus metas llevar a cabo programas para la cooperación y el desarrollo sostenido de la República Dominicana y facilitar el retorno voluntario de los inmigrantes. El principal objetivo de AESCO es promover proyectos de desarrollo en América Latina, buscando la manera de que las mejores oportunidades y la mejora de la condición de inmigrante se traduzcan en una creación de conciencia e implicación en el desarrollo de su país de origen. En ATIME se considera que la cooperación con el país de origen de los asociados es necesaria y esencial para alcanzar el deseado equilibrio Norte-Sur; es por eso que, junto con otras ONG marroquíes, participa en los programas de cooperación diseñados por la Unión Europea para Marruecos.

Realmente, esta apuesta por el desarrollo del país de origen de los inmigrantes también aparece en el diseño de la política europea de inmigración. Efectivamente, el segundo eje de esta política es la cooperación internacional, reducir los flujos de entrada a través de la colaboración con los países de origen de los inmigrantes, es decir, evitar que se produzca la emigración mejorando las condiciones económicas en los países emisores mediante políticas de cooperación y ayuda al desarrollo. Ahora bien, hasta la actualidad, la Unión Europea no ha hecho grandes esfuerzos en este campo, más bien al contrario, el gasto destinado a la ayuda al desarrollo se ha visto disminuido. En este contexto, podemos entender mejor el énfasis puesto en este punto por las asociaciones de inmigrantes.

\section{Procesos de construcción de los marcos de interpretación}

A comienzos de la década de 1990 crece el número de asociaciones de inmigrantes radicadas en España y se detecta una mayor diversificación ideológica 
en las mismas. Tres son los factores que provocan la gestación de un «clima social» que propicia la politización de la situación de los inmigrantes en España, dos relacionados con brotes xenófobos y racistas de extrema gravedad y con gran difusión en los medios de comunicación ${ }^{10}$ y uno relacionado con el polémico giro producido desde el año 2000 en la política de extranjería española. Después de un pormenorizado análisis de los documentos y las declaraciones de las asociaciones de inmigrantes, se detectaron en sus discursos tres narraciones o frames principales: el primero, denominado «marco identitario-multicultural», el segundo, "marco de la dependencia» y el tercero, «marco de los derechos de ciudadanía». A continuación, pasamos a analizarlos, utilizando el protocolo establecido por los postulados teóricos del «marco de interpretación» (autodefinición, objetivos, temáticas, problemáticas, causas, causantes y soluciones) y restringiendo nuestros comentarios a los textos y discursos explícitos de estas asociaciones, lo que nos permite articular el marco teórico con la evidencia empírica de nuestro objeto de estudio.

\subsection{Marco identitario multicultural}

Este marco se apoya en la asunción de la existencia de un «nosotros-otros» que descansa en las diferencias culturales entre la sociedad de acogida y la de origen. El modelo elegido por las asociaciones es el multicultural, entendiendo por tal el derecho a ser diferente, el reconocimiento de ambas culturas en pie de igualdad (Taylor, 1993). La identidad colectiva emerge cuando se produce el contacto con la sociedad de acogida. Efectivamente, es este contacto el que hace patentes las diferencias culturales, siendo una de las más destacables la religión, detectándose en los latinoamericanos sus peculiaridades cristianas y en los magrebíes, sus cultos musulmanes. Las diferencias se hacen visibles en el diseño de las páginas webs de estas asociaciones, que utilizan elementos tradicionales como la música, el estilo gramatical de sus textos (y a veces el uso simultáneo de su lengua autóctona y del castellano), el empleo de colores de su bandera nacional, la inclusión de estampas típicas de su país y de sus gentes, la aparición de toponimia propia, la venta de artesanías, la publicidad de las celebraciones festivas de su país, etc.

La reivindicación de estas organizaciones es dual: por un lado, intentan difundir en la sociedad española su riqueza cultural y fomentar la socialización de su propia cultura entre los inmigrantes de primera y de segunda generación; por otro lado, quieren enseñar a los inmigrantes la cultura española. En este sentido, la enseñanza del idioma ocupa, para las asociaciones de inmigrantes no hispanohablantes, un lugar privilegiado.

La referencia al pasado que realizan las organizaciones de latinoamericanos, invocando lazos históricos y culturales, de convivencia enriquecedora entre la cultura española y las culturas aborígenes, la aceptación de la «Madre Patria» 
como referente fundamental de su identidad nacional, es la principal argumentación para legitimar las altas posibilidades de éxito del modelo multicultural propuesto. En el caso de las organizaciones magrebíes, es la mítica convivencia entre cristianos, judíos y musulmanes en Al Andalus a lo largo de varios siglos la que ejemplifica el éxito de esta fórmula.

El modelo de integración cultural por asimilación, practicado por las sociedades europeas hasta la década de 1980, es una de las dificultades para construir y desarrollar un contexto de convivencia intercultural. Además, en la década de 1980, España deja de ser un país emisor de emigrantes y se convierte, en la década de 1990, en un país receptor de inmigrantes, y es precisamente la inexperiencia en este tipo de realidades uno de los elementos que dificulta la gestión madura y sosegada de esta nueva situación. La temática de la narración de estas organizaciones es la multiculturalidad como un hecho deseable. Si no se produce la multiculturalidad, surgirá el problema de la discriminación, la exclusión y la aniquilación de la cultura del inmigrante en beneficio del modelo étnico dominante en la sociedad de acogida y, en situaciones extremas, este modelo impuesto puede llegar a generar xenofobia y racismo.

\subsection{Marco de la dependencia}

El nombre de este marco hace honor a las teorías económicas que, durante la segunda mitad del siglo XX, dominaron el pensamiento teórico en América Latina, y que tuvo su máxima expresión con los economistas de la CEPAL (Comisión Económica para América Latina). La tesis se articula entorno a las relaciones asimétricas establecidas entre el centro y la periferia del sistema capitalista mundial. Bajo esta argumentación, los pueblos del Sur padecen fuertes procesos de crisis económica originados por las desigualdades mundiales en el reparto de la riqueza y en la explotación de sus recursos. Esta estructura mundial asimétrica es la que genera el flujo de masas humanas en busca de fuentes de empleo y riqueza, en un doloroso proceso de abandono de sus contextos de origen. El causante, por lo tanto, es el sistema capitalista mundial y, más concretamente, los países más beneficiados por este modelo, que, paralelamente, son los receptores de estos flujos humanos. Secundariamente, también se reconoce el negativo papel desempeñado por las propias elites nacionales, que reproducen un sistema de colonialismo interno, de corte autoritario y corrupto, modelo que elimina cualquier esperanza de cambio para estos pueblos.

Es por ello que una de las soluciones propuestas se relaciona con las políticas de la cooperación para el desarrollo. La estrategia consiste en llevar los puestos de trabajo a los pobres, evitando que los pobres se vean obligados a emigrar. Desde el punto de vista teórico, las actuaciones pueden enmarcarse en tres niveles (Mármora, 2002): el macroeconómico mundial (incidiendo sobre las condiciones estructurales que provocan los movimientos migratorios), el de los espacios de integración regional (creando espacios de integración que disminuyan las asimetrías económicas entre los estados miembros) y el de la retención focalizada (a través de la promoción económica y social de las 
áreas emisoras o a través de la cooperación internacional con estas áreas). Si no se llevan a cabo políticas de cooperación al desarrollo a favor de los países emisores, la salida de emigrantes continuará. Lógicamente, también se incide en la importancia del papel desempeñado en los países de origen y, en concreto, de su compromiso con el desarrollo interno.

\subsection{Marco de los derechos de ciudadanía}

Este marco intenta legitimar las acciones colectivas encaminadas a garantizar los derechos integrales del colectivo inmigrante. Se trata de reconocer a las denominadas "comunidades trasnacionales», formadas por inmigrantes de dos o más nacionalidades, y se habla de la creación de una "ciudadanía mundial». En este sentido, la normalización de los inmigrantes en España pasaría por su reconocimiento como ciudadanos de la Unión Europea o incluso como ciudadanos del mundo.

El punto de partida de este marco es la Declaración de los Derechos Humanos de 1948, de la cual se deriva una concepción de ciudadanía integral que engloba derechos de primera, segunda y tercera generación (Marshall, 1998; Martínez de Pisón y Giró Miranda, 2003), es decir, los referidos al ámbito de lo económico, de lo sociocultural y de lo político, respectivamente. Las asociaciones de inmigrantes denuncian la violación sistemática de los derechos de ciudadanía del colectivo de extranjeros. Según ellos, el inmigrante sólo es considerado en su condición de fuerza de trabajo, y en la mayoría de las ocasiones accede a los trabajos que los autóctonos no quieren ocupar, con una clara limitación de sus derechos laborales (o con ausencia total en el caso de los indocumentados). Por lo tanto, los otros ámbitos de la ciudadanía, como el acceso a los servicios públicos o el derecho a la participación política, sólo son disfrutados por un reducido grupo de inmigrantes, pero nunca en igualdad con los españoles ${ }^{11}$.

Las causas y los causantes de la limitación de estos derechos son las restricciones legales y normativas impulsadas desde el gobierno, que finalmente acaban beneficiando, por una parte, a un sector del empresariado español, que mantiene así sometida a una mano de obra barata y sumisa y, por otra, a las redes que trafican con inmigrantes.

\section{Relación entre los marcos y las situaciones analizadas}

Todas las organizaciones analizadas se caracterizan por la presencia de uno, dos o tres de los «marcos de interpretación» que se han determinado. Entre aquellas asociaciones que presentan en su ideario los tres frames, uno de ellos

11. Es significativo el cambio del título del artículo 3 de la Ley de extranjería española: en la Ley Orgánica 4/2000, se titulaba Igualdad con los españoles e interpretación de las normas, pasando a denominarse en la Ley Orgánica 8/2000, Derechos de los extranjeros e interpretación de las normas. 
es el que suele destacar, bien porque es tratado con énfasis y/o dramatización, bien porque se le dedica una gran extensión en sus manifiestos públicos.

En una escala de complejidad de los discursos ideológicos esgrimidos por estas asociaciones, en un extremo se localizan ASCIB, VOMADE y ACHE. En estas tres organizaciones, destaca la sencillez de sus mensajes que enfatizan un único frame frente a los demás: el «identitario-multicultural». Un ejemplo de como se muestra este frame se observa en ASCIB. Así, en la presentación de la página web de esta asociación, puede leerse: «[...] los inmigrantes tienen la necesidad de dedicarse a resolver problemas relacionados con la subsistencia y la obtención de permisos de trabajo y residencia, con el inexcusable olvido del futuro de sus hijos, su educación y su identidad cultural» y también «[...] queremos fomentar el intercambio cultural: dar a conocer los aspectos más relevantes de nuestra cultura y facilitar la comprensión de la cultura del país de acogida para crear un clima de tolerancia, convivencia y respeto». El «marco de la dependencia» no aparece en el discurso de estas asociaciones; de hecho, en ningún momento se hace la más mínima referencia a las causas que provocan las migraciones y, por lo tanto, tampoco se ofrecen soluciones. Sin embargo, el "marco de los derechos de ciudadanía» tiene relativa importancia en ASCIB, VOMADE y ACHE; aquí el discurso es muy moderado, ya que se ofrecen servicios sociales (asesoramiento jurídico a inmigrantes, servicio de traducción, integración sociolaboral de hombres y mujeres, atención a los menores, etc.), de lo que se deduce que existe una deficiencia en la oferta pública de estos servicios, pero no se comentan ni las causas ni los agentes causales de esta situación deficitaria; además, no aparece ninguna referencia a los derechos políticos.

En el otro extremo de la escala, se ubican las organizaciones ATIME y ARIPerú, organizaciones que destacan por el manejo de los tres frames de forma altamente politizada, y muy próximo a éstas se sitúan AESCO y ACULCO, caracterizadas por el alto grado de desarrollo y madurez del «frame de los derechos de ciudadanía», que se apoya en una argumentación sobre la identidad multicultural de trascendental calado. Ejemplificando el polo más extremo, la asociación ATIME representa esta politización de la situación del inmigrante. En la presentación de su página web, puede leerse: «[...] ATIME se crea en 1989 por iniciativa de un grupo de personas unidas tanto por la amistad como por una situación personal común: ser nacionales marroquíes que por circunstancias económicas y/o políticas tuvieron que abandonar su país y trasladarse a España bajo la condición de emigrante económico o de refugiado político». La causa mencionada es «[...] la injusticia, la mala gestión y la falta de democracia, razones éstas, en definitiva, que nos han obligado a salir de nuestro país». Y el objetivo proclamado es «[...] la transformación de las causas de la pobreza e inestabilidad de los países del sur del Mediterráneo para lograr el desarrollo necesario y disfrutar de la vida que a toda persona, por justicia social, le pertenece». En ATIME, dentro del «marco de los derechos de ciudadanía», también se plantea otro tema: «[...] un tratamiento más justo del colectivo de inmigrantes residentes en España, en un momento en que sus libertades y dere- 
chos fundamentales están siendo menoscabados por un marco legal y jurídico excesivamente restrictivo que vulnera su condición tanto de ciudadanos como de seres humanos». Por lo tanto, para esta asociación, la limitación de los derechos de los inmigrantes es el resultado del marco legal existente.

En ATIME, ARI-Perú, AESCO y ACULCO, el «marco de la dependencia» tiene relativa importancia, aunque no está politizado, pues no se citan dentro de los agentes causales del subdesarrollo de sus países las relaciones Norte-Sur. También el «marco identitario-multicultural» tiene bastante importancia en estas asociaciones. En la página web de ATIME, bajo el título "Destinos diferentes, historia común", se realiza un breve repaso histórico que se remonta al siglo X, momento en el que se consolida Al Andalus, espacio de convivencia pacífica de varias culturas y religiones (árabes, bereberes, europeos, cristianos, musulmanes, judíos y africanos), y es precisamente esta coexistencia pacífica la que ejemplifica el éxito de la fórmula multicultural propuesta por esta asociación. Sin embargo, la expulsión de los no cristianos en la época de los Reyes Católicos rompe esta convivencia; las hostilidades continúan hasta la actualidad, y se cita como ejemplo más reciente «[...] el protectorado e intervención militar de España en Marruecos [...] dejó unas huellas importantes y muy marcadas en la relación entre ambos pueblos». La identidad marroquí surge por el contacto con la sociedad de acogida, ya que se afirma: «[...] el marroquí no tiene necesidad de defenderse como musulmán en Marruecos».

En medio de esta gradación, se localizan AESCO y AICODE, asociaciones que también hacen referencia a los tres marcos analizados, aunque con un tratamiento menos complejo que en ATIME y ARI-Perú. En AESCO y AICO$\mathrm{DE}$ destacan las referencias al «frame de la dependencia», aunque no se mencionan las causas ni los agentes causales de la situación de subdesarrollo que padecen los países latinoamericanos. En los objetivos que se plantean en AICODE, se observa esta presencia de los tres frames: «[...] desarrollo de los principios de la interculturalidad y la tolerancia» («marco identitario-multicultural»); «[...] defensa de los derechos humanos, reafirmando el valor de la persona, particularmente de los más desfavorecidos» («marco de los derechos de ciudadanía») y "[...] promocionar, desarrollar y consolidar programas orientados a la divulgación y defensa de los principios de la Cooperación al Desarrollo con los Países y pueblos de América Latina» («marco de la dependencia»).

Finalmente, aunque no se ha detectado un frame sobre género en ninguno de los idearios analizados, son evidentes las referencias de esta temática en todas las asociaciones analizadas, unas veces a través del apoyo explícito a los colectivos de mujeres mediante actividades y servicios concretos (como en el caso de ASCIB, ATIME y AICODE) y otras veces mediante el liderazgo de las mujeres en estas organizaciones (como en el caso de VOMADE, que se funda en torno al ya mencionado asesinato de Lucrecia Pérez, y que incluye el sustantivo madres en el nombre de su asociación). También merece una mención especial la atención a la infancia, con programas y actividades específicos para la integración y educación en la mayoría de las organizaciones estudiadas. 
De todo lo anterior, se deduce que existen tres tipologías de organizaciones en función del tratamiento más o menos intenso del discurso ideológico esgrimido. El primer grupo se caracteriza por la escasa politización de la temática del inmigrante, e incluso el uso de un único frame, el identitario-multicultural. El segundo destaca por el mayor énfasis a los tres frames, aunque de un modo muy moderado, de hecho, el frame más reivindicativo, el de la dependencia, apenas se desarrolla. Por último, se identifica aquella tipología de organizaciones con alto grado de politización, donde el «frame de la dependencia» es el central, ya que las relaciones Norte-Sur son consideradas las causantes de los movimientos migratorios.

\section{Impacto en las audiencias y resonancia de los discursos}

Para que un "proceso de enmarcamiento" sea eficaz y consiga el éxito del proyecto político del movimiento que lo abandera, es necesario que se generen «alineamientos» $\mathrm{y}$ «resonancias» dentro de la propia corriente y fuera de ella, con las «audiencias» a las que va destinado (Snow y otros, 1993; Gamson, 1990). Para evaluar la eficacia de la argumentación política utilizada por las distintas asociaciones de inmigrantes, es imprescindible conocer el impacto de sus discursos en los diferentes actores sociales, pues el éxito del discurso estará condicionado por las similitudes entre éste y la postura ideológica dominante entre estos actores. En relación con la temática migratoria, se pueden establecer cuatro audiencias principales: la interna (referida al propio colectivo de inmigrantes), la sociedad civil de acogida, la institucional y la organizacional (formada por la red de asociaciones de todo tipo). A continuación, se realiza una breve aproximación a cada una de ellas, que deberá ser ampliada y completada en próximos estudios que trascienden los objetivos de este artículo. Por lo tanto, consideramos que es fundamental advertir al lector de las limitaciones de este análisis, pues no ha ido acompañado de un exhaustivo trabajo de campo a través de entrevistas en profundidad, encuestas, grupos de discusión y otra serie de metodologías de análisis destinadas al estudio de los discursos y opiniones de los actores que conforman a los colectivos de inmigrantes, a la sociedad civil, a las organizaciones de la sociedad civil y a las instituciones de la Administración pública.

En la primera «audiencia», se evalúan los impactos de los «procesos de enmarcamiento» dentro del propio movimiento asociativo. En este caso, los «alineamientos» del marco deben relacionar las interpretaciones de cada uno de los inmigrantes (intereses, valores y creencias) con las disquisiciones de la organización que estructura y dirige el movimiento social (ideología, actividades y objetivos) (Snow y otros, 1993). Esta «estrategia de enmarcamiento» pretende generar una representación de la «identidad propia» dentro de las comunidades de inmigrantes, mediante los intentos de localización de «alineamientos» entre el «mundo de vida» de cada uno de los inmigrantes y el «mensaje» de la organización.

En este punto, entendemos que es muy importante aclarar el vacío existente en la literatura académica sobre la temática migratoria relativa al análisis 
de la opinión pública del colectivo de inmigrantes que residen en el territorio español, lo que sin duda limita las interpretaciones que a continuación desarrollamos. Esta carencia imposibilita conocer el grado de politización del colectivo inmigrante y, por lo tanto, estimar el potencial movilizador que tiene el discurso de las asociaciones de inmigrantes entre la población extranjera.

Se evidencia que existen conexiones (frame brigding) (Snow y otros, 1993) entre el marco identitario-multicultural, el marco de la dependencia y el marco de los derechos de ciudadanía con sus «estructuras cognitivas y simbólicas», con su «bagaje cultural» y con la «fidelidad narrativa» de su historia, como se evidencia en los relatos relacionados con el pasado colonial latinoamericano y con la reconquista cristiana. Las amenazas y los problemas que destacan los «marcos» coinciden con lo que experimentan cotidianamente los inmigrantes: brotes racistas, marginación social, explotación laboral, discriminación cultural, etc., lo que favorece entre los inmigrantes la credibilidad empírica del marco generado desde estas organizaciones y refuerza la actitud exofóbica (Mármora, 2002: 54) entre los inmigrantes.

La segunda «audiencia» se refiere a los efectos de estos tres «marcos políticos inmigrantes» entre la opinión pública española.

Una vez más, debemos destacar la ausencia de investigaciones recientes sobre este tópico. De hecho, las últimas investigaciones publicadas son las elaboradas en España por el Centro de Investigaciones Sociológicas (CIS) y por Análisis Sociológicos, Económicos y Políticos (ASEP) y que corresponden a los años 1996 y 1997, respectivamente (Vallés y otros, 1999: 50). Los resultados de estos estudios indican una actitud claramente negativa por parte de la población española ante la inmigración. Por ejemplo, en la encuesta del CIS 1996, los resultados muestran el predominio de la opinión de que los inmigrantes quitan los puestos de trabajo a los españoles y reducen los salarios; en la misma encuesta, los españoles apuestan mayoritariamente por una política muy restrictiva con la entrada y permanencia de inmigrantes. Sin embargo, anteriormente comentábamos que el auge de la inmigración en España se produce en la segunda mitad de la década de 1990, es decir, posteriormente a la realización de estas investigaciones. Todo esto limita el análisis de cualquier pesquisa que pretenda medir la actitud de la opinión pública ante la inmigración.

Definitivamente, los intentos de «sensibilización» sobre la problemática de la emigración han sido un relativo fracaso. Por un lado, el distorsionado y escaso eco que las cuestiones migratorias mantienen en los medios de comunicación de masas del país, que únicamente cubren las noticias sobre esta temática cuando se produce una catástrofe, propician la vinculación «imaginaria» entre delincuencia e inmigración, muy negativa para este colectivo (Vallés y otros, 1999).

Por otro lado, la configuración de la conciencia nacional, que se ha construido desde una visión unidimensional, de espaldas a la pluralidad étnica, negando e invisibilizando del inconsciente colectivo histórico otras realidades culturales, favorece la visión peyorativa y xenófoba del «otro». Si a esto se añade 
el componente ideológico neoliberal dominante (master frame) (Gamson y Meyer, 1999: 396), que propicia la competitividad en el seno de la clase trabajadora, se deduce que el choque entre este «icono político» neoliberal (Klandersman y otros, 1988) y el mencionado "marco de la dependencia» resulta de difícil conciliación.

La tercera audiencia, referida al nivel del estado, se apoya en la escasa institucionalización de la reciente realidad inmigratoria, realidad que sólo cuenta con una década de historia. Aunque en la legislación española en materia de extranjería se considera a los inmigrantes extracomunitarios como un único colectivo, la aplicación de las políticas están demostrando una clara preferencia por el grupo de latinoamericanos, colectivo que es visto más asimilable con la matriz sociocultural española (Izquierdo y otros, 2003).

Otra «audiencia» con la que sí han conseguido el éxito deseado, la componen los grupos de presión (sindicatos, organizaciones empresariales, partidos políticos, instituciones religiosas, ONG y asociaciones de inmigrantes y de defensa del inmigrante). Estos grupos han llegado a «institucionalizar» un importante número de "políticas sociales» que suplen la carencia de servicios no ofertados por el Estado a los inmigrantes. Estos resultados no se encuentran respaldados por un análisis exhaustivo del movimiento asociativo espanool, más bien se trata de una aproximación cualitativa a partir del análisis de las actividades más significativas llevadas a cabo por estas organizaciones, aunque esta forma de operar no invalida los resultados aquí presentados.

\section{Conclusiones}

Es un hecho indiscutible que en las viejas sociedades europeas se están haciendo visibles diferencias culturales y étnicas. La inmigración en la estructura social y política está poniendo de manifiesto la existencia de grupos sociales con sus propias identidades, como signos inequívocos de falta de homogeneidad social. Estos hechos han puesto en crisis el viejo ideal de ciudadanía e igualdad del proyecto político de la modernidad. El concepto de multiculturalidad nos remite a la diversidad cultural y al pluralismo, por lo tanto, a las diferencias. La cuestión a debatir es si una sociedad debe proteger y exaltar las diferencias en su irreductibilidad, o bien deben buscarse valores universales que hagan compatible las diferencias y garanticen la unidad social. Hechos tan dramáticos como los que muestran los brotes racistas en nuestro país, que se han acentuado a partir del reciente atentado del 11 de marzo del 2004 en Madrid, perpetrado por grupos extremistas islámicos, ejemplifican las dificultades que debe sortear la iniciativa sociopolítica que pretenda «realizar políticas de inmigración", más que «hacer política con la inmigración» y que reclame la consecución de una ciudadanía cívica universal (Martínez de Pisón y Giró, 2003: 44).

En este texto, se ha pretendido mostrar la realidad actual del discurso del inmigrante organizado a través del análisis de las asociaciones de inmigrantes del Foro para la Integración Social de los Inmigrantes. Tal y como se pone de 
manifiesto en esta investigación, el nacimiento de estas asociaciones estuvo estrechamente vinculado a una "estructura de oportunidad política» (McAdam y otros, 1999) concreta, es decir, a un contexto histórico caracterizado por la polarización de la estructura social mundial que, al mismo tiempo que concentra la riqueza, incrementa la pobreza. Y también por el proceso de consolidación de la inmigración en España y el endurecimiento del marco legal español en torno a las políticas migratorias, agravados por los sucesos de racismo y xenofobia que en estos años han sacudido a la sociedad española. En este sentido, la modificación de estos contextos va a influir en el discurso de estas organizaciones, de tal forma que la tipología establecida en este trabajo, va a sufrir mutaciones en un futuro próximo.

El análisis de los documentos y las declaraciones de las asociaciones del Foro para la Integración Social de los Inmigrantes nos ha permitido detectar en sus discursos tres narraciones o frames. El primero, el «marco identitario-multicultural", se apoya en la existencia de diferencias culturales entre la sociedad de acogida y la de origen; según estas asociaciones, estas diferencias se pueden hacer compatibles a través de un modelo multicultural, modelo que defiende el derecho a ser diferente, la defensa de la cultura de origen y el respeto por la cultura de acogida. El segundo, el "marco de la dependencia», se centra en las diferencias entre el centro y la periferia como causantes de los flujos migratorios mundiales; en este sentido, la solución propuesta por estas asociaciones es la cooperación internacional, la ayuda al desarrollo a los países emisores para evitar que las migraciones se produzcan. El tercero, el «marco de los derechos de ciudadanía», trata de legitimar los derechos integrales del colectivo inmigrante, equiparar al extranjero con el autóctono, conseguir que el inmigrante sea considerado un ciudadano más, y no sólo un trabajador y, para conseguirlo, estas asociaciones luchan por cambiar la legislación actual en materia de extranjeros.

En función del tratamiento más o menos intenso del discurso ideológico esgrimido por las asociaciones del Foro para la Integración Social de los Inmigrantes, hemos podido identificar tres tipologías de organizaciones. El primer grupo se caracteriza por la escasa politización de la temática del inmigrante, e incluso el uso de un único frame, el identitario-multicultural. El segundo destaca por el mayor énfasis a los tres frames, aunque de un modo muy moderado, de hecho, el frame más reivindicativo, el de la dependencia, apenas se desarrolla. Por último, se identifica aquella tipología de organizaciones con alto grado de politización, donde el «frame de la dependencia» es el central, ya que las relaciones Norte-Sur son consideradas las causantes de los movimientos migratorios.

Con este artículo, se inicia una línea de investigación más amplia que pretende extender el espectro de entidades analizadas más allá del Foro para la Integración Social de los Inmigrantes, identificar otros frames y describir más pormenorizadamente el contenido de los mismos. Esperamos que el presente trabajo contribuya a dar cuenta de que diferenciar no equivale a discriminar y de que diversidad no equivale a desigualdad. 


\section{Bibliografía}

Berger, P.; LuCKMAN, T. (1984). La construcción social de la realidad. Buenos Aires: Amorrortu.

Cohen, J.L.; Arato, A. (2000). Sociedad civil y teoría política. México: FCE.

Colectivo IOE (1991). Situación y problemática de los inmigrantes en España. Madrid: Cáritas Española.

Colom, F. (1998). Razones de identidad: pluralismo cultural e integración politica. Barcelona: Anthropos.

DE LuCAS, J. (1993). El concepto de solidaridad. México: Fontamara.

EDER, K. (1992). Framing and Communicating Environmental Issues. A Discourse Analysis of Environmentalism. Flerence: European University Institute.

Gamson, W. (1990). The strategy of social protest. California: Wadsworth Publ.

GAMSON, W.; MEYER (1999). "Oportunidades políticas del frame». En MCADAMS, D.; MCCARTHY, J.; ZALD, M. (comp.). Movimientos sociales: perspectiva comparada. Madrid: Itsmo.

GERHARDS, J. (1995). Framing dimensions and framing strategies: contrasting ideal-and real-type frames. Londres: Social Science Information.

Giddens, A. (1995). Modernidad e identidad del yo. Barcelona: Debate.

Goffman, E. (1974). Frame analysis. Cambridge: Harvard University Press.

Goytisolo, J.; Nair, S. (2000). El peaje de la vida. Madrid: Aguilar.

Habermas, J. (1999). La inclusión del otro. Trad. de M. Eskaniz. Barcelona: Paidos.

IBARra, P.; Tejerina, B. (comp.) (1998). Los movimientos sociales. Madrid: Trotta.

IzQuierdo Escribano, A.; López de Lera, D.; MARTínez BujÁN, R. (2003). «The

favorites of the Twenty-First Century: Latin American Inmigration in Spain».

Studi Emigrazione, n. ${ }^{\circ}$ 149, p. 98-124.

KLADERMANS y otros (eds.) (1988). From structures to action: comparing social movements research across cultures. Conecticut y Londres: Jai Press lc.

KRIESI, H. (1992). «El contexto político de los nuevos movimientos sociales en Europa Occidental». En: BENEDICTO, J.; REINARES, F. Las transformaciones de lo político. Madrid: Alianza.

KyMLICKA, W. (1996). Ciudadanía multicultural. Una teoría liberal de los derechos de las minorías. Trad. de C. Castells. Barcelona: Paidós.

La Calle Marcos, A. (2002). "La construcción de la política comunitaria de inmigración». En: PIMENTEL Siles, M. (coord.). Procesos migratorios, economía y personas. Almería: Instituto Cajamar.

LAMO DE EsPinOSA, E. (1995), «Fronteras culturales». En: LAMO DE EsPinOSA, E. (ed.). Culturas, estados, ciudadanos. Madrid: Alianza.

León, E.; Zemelman, H. (1998). Subjetividad: umbrales del pensamiento. Barcelona: Anthropos.

LORENZO CADARSO, P.L. (2001). Fundamentos teóricos del conflicto social. Madrid: Siglo XXI. MÁIz, R. (1995). "La construcción de las identidades políticas». Revista Vasca de Sociología y Ciencia Politica, Inguruak, n. ${ }^{\circ} 13$.

MÁrmORA, L. (2002). Las políticas de migraciones internacionales. Buenos Aires: Paidos. Marshall, T.H. (1998). Ciudadanía y clase social. Madrid: Alianza.

Martínez de Pisón, J.M.; Giró MirandA, J. (2003). Inmigración y ciudadanía: perspectivas sociojurídicas. Logroño: Universidad de La Rioja.

McAdams, D.; McCARTHY, J.; ZALD, M. (comp.) (1999). Movimientos sociales: perspectiva comparada. Madrid: Itsmo. 
MeluCCI, A. (1995). Los nuevos movimientos sociales. De la ideología a la identidad. Madrid: CIS.

NAVARro, J.M. (1998). El Islam en las aulas. Barcelona: Icaria. Nussbaum.

Olson, M. (1971). The logic of colletive Action. 2a ed. Cambrigde (Mass): Harvard University Press.

Peces Barba, G. y otros (1995). Curso de derechos fundamentales. Madrid: BOEUniversidad Carlos III.

Pérez LuÑo, A.E. (1995). Derechos Humanos, Estado de Derecho y Constitución. Madrid: Tecnos.

SARTORI, G. (1993). La democracia después del comunismo. Madrid: Alianza.

SNOW, HunT y BENFORD (1993). Framing proceses and identity construction in collective action. Chicago. Presented at the Annual Meetings of the Midwest Sociological Society.

Solanes Corella, A. (2000). «Formas legales de exclusión de los extranjeros en España: ciudadanía, jerarquía de derechos y empadronamiento». II Congreso sobre la inmigración en España. España y las migraciones internacionales en el cambio de siglo. Madrid, 5-7 de octubre de 2000.

TARROW, S. (1997). El poder del movimiento. Los movimientos sociales, la acción colectiva y la política. México DF: Alianza Editorial.

TAYLOR, C. (1993). El multiculturalismo y la "política del reconocimiento». México: FCE.

Vallés Martínez, M.S.; Cea d’AnCona, M.A.; IzQuierdo Escribano, A. (1999). Las encuestas sobre inmigración en España y en Europa: Tópicos, medios de comunicación y politica migratoria. Madrid: Ministerio de Trabajo y Asuntos Sociales. WALLERSTEIN, I (1979). El moderno sistema mundial. Madrid: Siglo XXI.

\section{Webs de interés}

http://www.ascib.net

http://www.atime.es

http://www.aicode.org http://www.vomade.org http://www.ari-peru.org http://www.ongaesco.org 